\title{
New Modeling of AgFeNi2S4-Graphene-TiO2 Ternary Nanocomposite with Chelate Compounds and Its Photocatalytic Reduction of $\mathrm{CO} 2$
}

\section{Zambaga Otgonbayar}

Hanseo University

Chong Hun Jung

Korea Atomic Energy Research Institute

Oh Won-Chun ( $\nabla$ wc_oh@hanseo.ac.kr)

Hanseo University https://orcid.org/0000-0002-0154-7388

\section{Original Research}

Keywords: Graphene, Chalcogenide, Ternary composite, CO2 reduction, Methanol

Posted Date: February 4th, 2021

DOl: https://doi.org/10.21203/rs.3.rs-173213/v1

License: (c) (1) This work is licensed under a Creative Commons Attribution 4.0 International License.

Read Full License

Version of Record: A version of this preprint was published at Journal of Materials Science: Materials in Electronics on March 11th, 2021. See the published version at https://doi.org/10.1007/s10854-02105640-z. 


\section{Abstract}

Herein, we synthesized the chalcogenide-quaternary nanocomposite loaded Graphene-based ternary photocatalyst via a modified solvothermal method. The preparation of quaternary nanocomposite was based on metallic citrate polymerization which used ethylene glycol $\left(\mathrm{C}_{2} \mathrm{H}_{6} \mathrm{O}_{2}\right)$ and citric acid $\left(\mathrm{C}_{6} \mathrm{H}_{8} \mathrm{O}_{7}\right)$ as chelate cations. The morphology and electrochemical properties of the as-prepared nano-material investigated by using a physical characterization equipment. Each result showed that the ternary photocatalyst was successfully synthesized and showed the low recombination rate of photogenerated electrons and holes, which defined the catalytic activity of the photocatalyst for $\mathrm{CO}_{2}$ evolution into hydrocarbon fuels under light irradiation. In addition, the stability and reusability of the photocatalyst were analyzed by a 6-times cycling test without loss of methanol formation by $\mathrm{CO}_{2}$ evolution. The graphene-based ternary photocatalyst offers a new nanomaterial with a new-model that protects the environment by showing high catalytic activity in reducing $\mathrm{CO}_{2}$ to methanol.

\section{Introduction}

The increase in $\mathrm{CO}_{2}$ is the main cause of environmental pollution. There are several methods to reduce the $\mathrm{CO}_{2}$ from the atmosphere, such as photoreduction and electrochemical. Among them, $\mathrm{CO}_{2}$ conversion into solar fuel via the photocatalyst based method is an effective way to solve the problem. Nowadays, graphene-based chalcogenide photo-catalysts have high catalytic activity and variable band gap energy, which have been identified as the most promising catalysts in the process [1-3].

Transition-metal sulfide materials are the ideal choices for the photocatalyst. Especially, nickel sulfide is a low cost, a p-type semiconductor with $1.24 \mathrm{eV}$ band gap energy and a visible-light response [4-7]. Most importantly, it has a low Fermi level, which can capture the photo generated electrons because of its obvious tendency toward the metallic character. Transition metals ( $\mathrm{Ag}, \mathrm{Fe}, \mathrm{Cu}$, etc.) have unique properties, such as visible light response, inhibition of electron-hole recombination, and the role of strong electron receptors [8]. Based on the above properties, it is possible to combine nickel-sulfide with transition metals to produce quaternary nanocomposites with semi-insulating properties and high catalytic activity.

Coupling $\mathrm{TiO}_{2}$ with other semi-conductor can enhance the charge carrier property/ catalytic activity by adjusting their band gap position. For example, NiS decorated with $\mathrm{TiO}_{2}$ nanoflower exhibited a high photoactivity in hydrogen evolution has been reported $[9,10]$. The tradition $\mathrm{TiO}_{2}$ is the most widely studied semiconductor because it has high stability, cheap and strong oxidizing ability. However, pure $\mathrm{TiO}_{2}$ is somewhat limited in the photocatalytic field; because it is activated under UV light and $((<387 \mathrm{~nm})$ electrons and holes converge rapidly on the surface [11]. There are many techniques used to improve the properties of $\mathrm{TiO}_{2}$, such as surface modification and combining with low bandgap nano material $[12,13]$. A chalcogenide catalyst can be used to improve the photocatalytic properties of $\mathrm{TiO}_{2}$ in $\mathrm{CO}_{2}$ photocatalytic reduction. 
In this study, 2D graphene was used as a non-metallic co-catalyst to enhance the properties of the metalsemiconductor. Graphene has advantages such as high surface area, electronic conductivity, charge transfer and could function as a catalyst better than 0-D and 1-D nanomaterials [13-15].

The combination of the metal-semiconductor with graphene can strengthen the physical and chemical properties of graphene, which is a method for obtaining highly catalytically active nanocomposites [16]. In addition, the manufacturing of a ternary composite material has turned into an effective tactic to increase the absorption of solar light and photocatalytic capability $[17,18]$. The fabrication of ternary nanocomposites keeps many advantages to itself, such as adjustment of band gap energy, efficient charge carrier, and high catalyst activity. It is reported that the combination of two or more semiconductors provides these nano-architectural nanomaterials with new proeprties and access to new applications $[19,20]$.

Herein, the new-structured ternary $\mathrm{AgFeNi}_{2} \mathrm{~S}_{4}$-Graphene- $\mathrm{TiO}_{2}$ nanocomposite was synthesized via modified solvothermal method. The photocatalytic activity of the ternary photocatalyst was evaluated for the $\mathrm{CO}_{2}$ photoreduction under the light irradiation $(\lambda=254 \mathrm{~nm}$ and 565$)$ with two-different electron-donor scavengers. The catalytic activity test confirmed that the final ternary photocatalyst exhibits high activity for methanol production with $8.62 \%, 7.23 \%$. The morphological, optical and electrochemical properties of the ternary photocatalyst were studied and each results pointed-out that ternary nanocomposite was successfully synthesized.

\section{Experimental Setup}

\subsection{Materials}

Silver nitrate $\mathrm{AgNO}_{3}(\geq 98 \%)$, Iron (III) bitrate nonahydrate $\mathrm{Fe}\left(\mathrm{NO}_{3}\right)_{3} \cdot 9 \mathrm{H}_{2} \mathrm{O}(99.9 \%)$, Nickel (II) nitrate hexahydrate $\mathrm{Ni}\left(\mathrm{NO}_{3}\right)_{2} \cdot 6 \mathrm{H}_{2} \mathrm{O}(\geq 99 \%)$, Sodium thiosulfate $\mathrm{Na}_{2} \mathrm{~S}_{2} \mathrm{O}_{3}(\geq 99 \%)$, Citric acid $\mathrm{C}_{6} \mathrm{H}_{8} \mathrm{O}_{7}(\geq 99.5 \%)$, were procured from Duksan Pure Chemical Co. Ltd (Korea). Hydrochloric acid $\mathrm{HCl}$ (36 wt\%), Sulfuric acid $\mathrm{H}_{2} \mathrm{SO}_{4}(\geq 97 \%)$, Zinc nitrate hexahydrate $\mathrm{Zn}\left(\mathrm{NO}_{3}\right)_{2} \cdot 6 \mathrm{H}_{2} \mathrm{O}$ ( $\left.\geq 99.5 \%\right)$, Scavenger $\left(\mathrm{Na}_{2} \mathrm{SO}_{3}(97 \%), \mathrm{Na}_{2} \mathrm{~S}(98\right.$ $\%)$ ), were procured from Samchun Pure Chemical Co.LTD (Korea). The natural graphite powder is a precursor material of graphene. All chemical reagents had an analytical class and organic-solvents were used with deionized water.

\subsection{Synthesis of the quaternary nanocomposite}

The quaternary nanocomposite was synthesized by a hydrothermal method. The precursor solution was prepared using a 3: 2 ratio of ethylene glycol $\left(\mathrm{C}_{2} \mathrm{H}_{6} \mathrm{O}_{2}\right)$ and chelate-cationic citric acid $\left(\mathrm{C}_{6} \mathrm{H}_{8} \mathrm{O}_{7}\right)$. The 0.02:0.03:0.04:0.08 mmol ratio of precursor reagents were dispersed into the citric-acid solvent and stirred at $60{ }^{\circ} \mathrm{C}$ for $6 \mathrm{~h}$ until it becomes viscous. The process of preparing the mortar is called chelating, and its main function is to establish a chemical bond between the transition metal and the organic molecules in order to adjust the metal chain. 
The mixture was transferred into $100 \mathrm{ml}$ Teflon-line clave and heated at $150^{\circ} \mathrm{C}$ for $15 \mathrm{~h}$, then allowed it to cool to room temperature $\left(25^{\circ} \mathrm{C}\right)$. The final product was washed by DI-water and dried at $100{ }^{\circ} \mathrm{C}$; then the powder was calcined at $800{ }^{\circ} \mathrm{C}$ for $4 \mathrm{~h}$. The final nanomaterial was denoted as AFNS.

\subsection{Synthesis of ternary nanocomposite}

The binary and ternary composite prepared by a modified solvothermal method. The graphene was prepared by a Hummer Offeman's method [18] and more detailed information was described previously [22]. First, the organic solvent was prepared using absolute ethanol and DI water (volume ratio $=5: 4$ ) with continuous stirring at room temperature. Then, $0.7 \mathrm{~g}$ of the as-prepared AFNS added into the solvent, stirred it for $1 \mathrm{~h}$, and then added $0.5 \mathrm{~g}$ graphene. After stirring for $6 \mathrm{~h}$, transfer the solution to a $100 \mathrm{ml}$ Teflon-lined stainless-steel autoclave and heat-treated at $150^{\circ} \mathrm{C}$ for $15 \mathrm{~h}$, and then cooled to $25^{\circ} \mathrm{C}$. The final product is rinsed with DI water, dried at $90{ }^{\circ} \mathrm{C}$ until dry, and then calcined under the same conditions. The as-prepared sample was denoted as AFNSG.

The next step is $\mathrm{TiO}_{2}$ combined with AFNSG. The molar ratio of ethanol to $\mathrm{H}_{2} \mathrm{O}$ to TNB of $30: 15: 4$ and stirred it continuously for $1 \mathrm{~h}$. Add $0.5 \mathrm{~g}$ of AFNSG nanocomposites to the prepared solution, stirred at room temperature for $6 \mathrm{~h}$, then transfer the solution to an autoclave and kept in an electric oven at $150^{\circ} \mathrm{C}$ for $15 \mathrm{~h}$. The obtained product was rinsed with DI-water and dried until it became a powder, which was calcined under the same conditions. The final sample renamed AFNSGT. The morphology state and electrochemical analysis method was detailly explained in the supplementary material.

\section{$2.4 \mathrm{CO}_{2}$ photoreduction test of AFNSGT nanocomposite}

The photoreduction of $\mathrm{CO}_{2}$ was conducted in three-part closed reactor under the light irradiation (Scheme S1). Two different electron-donor scavengers were used in this experiment, which could provide a cyclicelectron supplier to increase the catalytic activity of the photocatalyst. First, $0.04 \mathrm{M} \mathrm{NaHCO}_{3}$ solution was prepared. Then, $0.1 \mathrm{~g}$ of photocatalyst and scavengers were dispersed in solvent and stirred for $1 \mathrm{~h}$. A high pure input gas $\left(\mathrm{CO}_{2}, 99.99 \%\right)$ was purged into the mixture to obtain a gas/solvent mixture; the gas was controlled by the mass flow controller and the total gas-purging time was $30 \mathrm{~min}$. Next, the pure nitrogen was purged into the mixture to remove the gas from the glass-reactor. The lamp was then switched on and the light source ( $500 \mathrm{~W}$ halogen lamp) was placed at the top of the reactor at a distance of about $10 \mathrm{~cm}$. The total reaction time was $48 \mathrm{~h}$, and the reactor was cooled every $12 \mathrm{~h}$. The final solution was withdrawn from the reactor using a syringe and a membrane filter with a pore size of 0.45 $\mu \mathrm{m}$.

The $500 \mathrm{~W}$ metal halide lamp as the light source, and the light source place at the top of the reactor which had a distance around $10 \mathrm{~cm}$. In this experiment, two different electron-donor scavengers were used, and it can provide a cyclic electron supplier which can boost the catalytic of the photocatalyst. In detail, the $100 \mathrm{mg}$ of photocatalyst and scavengers were dispersed in $0.04 \mathrm{M} \mathrm{NaHCO}_{3}$ containing $50 \mathrm{ml}$ solvent and stirred for $1 \mathrm{~h}$. The pure input gas was controlled by the mass flow controller and the total 
gas-purging time was $30 \mathrm{~min}$. The total reaction was 48 hours, and every 12 hours, a solution of a certain volume was withdrawn from the reactor using a syringe, and the solution was filtered through a membrane filter with a pore size of $0.45 \mu \mathrm{m}$ and a diameter of $47 \mathrm{~mm}$. The alcohol amount of the solution was analyzed by a "Quantitative analysis of alcohol" method. In alcohol analysis, $10 \mathrm{ml}$ of $0.1 \mathrm{M}$ $\mathrm{CrO}_{3}$ added into $1 \mathrm{ml}$ sample and agitated it for $15 \mathrm{~min}$, then centrifuged the suspension (10000 ppm/15 min). The concentration of acquired solution examined by a UV spectrophotometer (Optizen POP, Korea) using a quartz cell $(1 \mathrm{~cm} \times 4.5 \mathrm{~cm})$. The functional group of the final methanol was analyzed by a FTIR spectrometer (FTIR iS5, Thermoscience).

\section{Results And Discussion}

\subsection{Phase composition}

The crystal structures of all samples are shown in Figure 1. The XRD result basically expresses the characteristics of each sample. The XRD peak intensity of AFNSG and AFNSGT had become sharp, which showed that each sample had decent crystalline state. The FWHM amounts of the XRD-patterns were decreased and crystallite size increased due to the decent crystallinity of the AFNSG and AFNSGT nanocomposites.

The diffraction peaks were located at $2 \theta$ of 21.87 and $41.48^{\circ}$ assigned to the (112) crystal planes of $\mathrm{Ag}_{2} \mathrm{~S}$ (JCPDS. 14-0072). In addition, the diffraction peaks at $2 \theta$ of $30.92,37.75$ and $55.28^{\circ}$ were assigned to the crystal planes of $\mathrm{FeNi}_{2} \mathrm{~S}_{4}$ (JCPDS. 96-900-0979). Other diffraction peaks corresponded to the crystal phase of AFNS. After combining with graphene, the diffraction peak became sharp and the diffraction peak of Graphene was observed at $2 \theta$ of $14.41^{\circ}$, corresponding to the (100) crystal plane. The peak intensity was low because of less quantity. In AFNSGT nanocomposite, the XRD pattern of $\mathrm{TiO}_{2}$ were observed at $2 \theta$ of $25.14,48.01,55.12,62.71$ and $74.89^{\circ}$, which were assigned to the (101), (200), (121), (024) and (125) crystal planes of anatase $\mathrm{TiO}_{2}$ (JCPDS №.21-1272). The reference XRD peak of anatase $\mathrm{TiO}_{2}$ and ternary nanocomposite data was suggested in Figure $\mathrm{S} 1$. The catalytic activity of the anatase is more active than the rutile phase, the electron-hole pair life of anatase is favorable for the surface reaction. In addition, the crystal facet [(101), (010), (001)] of anatase had different catalytic activity. According to the obtained XRD result, an above-mentioned peak was observed, it is confirming that a combination of $\mathrm{TiO}_{2}$ and AFNSG can show high catalytic activity.

The crystallite sizes of each nanocomposite were calculated using a Debye-Scherrer equation and found them to be $9.04,12.65$, and $1.41 \mathrm{~nm}$. The crystallite sizes of a particle can affect the catalytic activity of the photocatalyst. There are several published research paper that analyzed the effect of crystallite size on photocatalytic performance.

The chemical states and interactions among $\mathrm{AgFeNi}_{2} \mathrm{~S}_{4}$, graphene, and $\mathrm{TiO}_{2}$ were analyzed by XPS analysis. Figure 2 shows the XPS spectrum of each element and the binding energy value depend on the chemical interaction and formation of the samples. Figure 2 (a) shows the two peaks at 368.44 and 
$378.15 \mathrm{eV}$ binding region, which are related to the Ag3d spectrum of $\mathrm{Ag}(\mathrm{I})$ in AFNSGT [23]. The XPS spectrum of Fe2p (Figure 2 (b)) displayed the four deconvoluted peaks 711.35, 714.34, 724.07, and $726.47 \mathrm{eV}$. The photoelectron peak at $711.35 \mathrm{eV}$ corresponds to the binding energy of $\mathrm{Fe}^{3+} 2 \mathrm{p}_{3 / 2}$; the peaks at $724.07 \mathrm{eV}$ can be assigned to the $\mathrm{Fe}^{2+} 2 \mathrm{p}_{3 / 2}$. The peak at $726.47 \mathrm{eV}$ can be corresponded to the $2 \mathrm{p}_{1 / 2}$ of $\mathrm{Fe}$ (II) and $\mathrm{Fe}$ (III) ion [24]. The last peak in the 714.34 binding-energy region is a satellite peak that indicates the coexistence of $\mathrm{Fe}$ (II) and $\mathrm{Fe}$ (III) in the quaternary nanocomposite. Figure 2 (c) shows the Ni2p XPS spectrum was deconvoluted into two spin-orbit doublets. The photoelectron peaks at 856.47 and $874.46 \mathrm{eV}$ indicate the $2 \mathrm{p}_{3 / 2}$ and $2 \mathrm{p}_{1 / 2}$ spin orbitals of $\mathrm{Ni}^{3+}$. The other two peaks assigned to the high spin divalent state (satellite peaks) of $\mathrm{Ni}^{2+}[25]$.

The S2p XPS spectrum consisted of four peaks, located in the 159.34, 160.19, 163.28, and $165.06 \mathrm{eV}$ binding-energy regions, as shown in Figure $2(\mathrm{~d})$. These four peaks can be assigned to monosulfide $\left(\mathrm{S}^{2-}\right)$ and disulfide $\left(\mathrm{S}_{2}{ }^{2-}\right)$ [26]. The XPS peaks of sulfide were placed at 158 161 eV, and the disulfide peaks were located in the 162 168 eV binding-energy region. The 01s spectrum is composed of four peaks, located in, the $529.51,530.39,531.63$ and $533.09 \mathrm{eV}$ binding-energy regions. The first-peak expresses the C-O group, whereas the second peak assigned to the metal-carbonate forms (0-Me) [27], as shown in Figure 2 (f) [28]. The existence of the metal carbonates form confirms the interaction between metal and oxygen. The next two peaks correspond to the carbonyl and carboxyl groups.

The high resolution Ti2p spectrum of AFNSGT displayed the two peaks at 458.85 and $464.75 \mathrm{eV}$, which are related to the $\mathrm{Ti}^{4+} 2 \mathrm{p}_{3 / 2}$ and $\mathrm{Ti}^{4+} 2 \mathrm{p}_{1 / 2}$. In addition, $2 \mathrm{p}_{3 / 2}$ spin-orbitals clearly determined the $\mathrm{Ti}$ (IV), and the ratio of these two peaks are 2:1, as shown in Figure 2 (g) [29].

\subsection{Morphology characterization}

The surface of the photocatalyst was analyzed via SEM and TEM. Figure 3 (a)-(f) show the SEM analysis of the quaternary, binary, and ternary nanocomposites. The quaternary nanocomposite had wrinkled and elliptical morphology, as shown in Figure 3 (a) and (b). After combining with Graphene, all particles agglomerated on the graphene exterior, because of the functional group of the graphene surface. The variously structured particles were irregularly agglomerated, as shown in Figure 3 (c)-(d). In SEM image of AFNSGT, the $\mathrm{TiO}_{2}$ particle showed the round and pentagonal structure. Figure $3(\mathrm{e})$ and (f) show the successful fabrication of the $\mathrm{AgFeNi}_{2} \mathrm{~S}_{4}-\mathrm{Graphene}_{-} \mathrm{TiO}_{2}$. Furthermore, the successful interconnection of the $\mathrm{AgFeNi}_{2} \mathrm{~S}_{4}$, Graphene and $\mathrm{TiO}_{2}$ can be helpful for the hetero-junction structure with the high charge carrier properties. Because the role of graphene is bridge and electron, acceptor which can support the photogenerated charge carrier and increase the photocatalytic capacity.

Additionally, the quantitative element analysis was explored by EDX instrument. Figure 3 (g) shows the microanalysis of all as-synthesized samples, which reveal the presence of the main elements. The Ag, Fe, $\mathrm{Ni}, \mathrm{S}, \mathrm{Ti}$, and $\mathrm{O}$ were obtained from the metal and metal-oxide component, and the $\mathrm{C}$ was derived from the 
main adsorbent material of graphene in the ternary photocatalyst. Each element had its own Ka and $\mathrm{K} \beta$ values in the proper region. These elemental analyses are summarized in the bit graph.

The internal structure and crystallographic facet of each nanocomposite are analyzed by TEM and HRTEM. Figure 4 (a) and (b) show the presence of the quaternary nanocomposite as elliptical with graphene, this result indicates the successful interaction of AFNS and graphene. The morphology of graphene was clear and provided the large surface needed for the metal compound to grow on the exterior, as shown in Figure $\mathbf{S} \mathbf{2}(\mathrm{a}, \mathrm{b})$.

Figure 4 (d) and (e) show that the pentagonal $\mathrm{TiO}_{2}$ occurred as dark-black and was uniformly spread on the graphene exterior in the AFNSGT ternary nanocomposite. $\mathrm{TiO}_{2}$ and quaternary nanocomposites are evenly distributed on the surface of graphene, and the oxygenated-functional group on the graphene exterior prevents the formation of metal or metal oxide agglomerates. Figure 4 (c) and (f) depicted the crystallographic facets of each nanocomposite via HRTEM. The lattice fringes with d-spacing values of the quaternary and $\mathrm{TiO}_{2}$, which were $0.236 \mathrm{~nm}$ and $0.353 \mathrm{~nm}$, which correspond to the AFNS (201) and $\mathrm{TiO}_{2}(101)$ crystal planes, respectively, as shown in Figure 4 (c) and (f). The average particle-size histogram with an interactive 3D surface plot of the quaternary, binary, and ternary nanocomposites are shown in Figure 5. The calculated average particle sizes were $3.29 \mathrm{~nm}$ (AFNS in AFNSG), $2.49 \mathrm{~nm}$ (AFNS in AFNSGT), and $2.85 \mathrm{~nm}\left(\mathrm{TiO}_{2}\right.$ in AFNSGT). The particle size state is shown in Figure 5 (a) (c). According to the 3D surface plot result, the roughness of AFNSG was uneven and convex, and the AFNSGT nanocomposite had a smooth-convex surface, as shown in Figure 5 (d).

The carbon material state ( $\mathrm{D}$ and G-band), molecular interaction between $\mathrm{AgFeNi}_{2} \mathrm{~S}_{4}$, graphene, and $\mathrm{TiO}_{2}$ were confirmed by performing the Raman spectroscopy. The full Raman data of the binary and ternary nanocomposites are shown in detail in Figure 6. Graphene had two sharp peaks in the 1337.87 and $1564.17 \mathrm{~cm}^{-1}$ shift region, which indicates the $A_{1 g}$ symmetry and $E_{2 g}$ symmetry (D mode and $G$ mode). The quaternary nanocomposite had two peaks in the 104.8 and $379.3 \mathrm{~cm}^{-1}$ regions. According to published articles, chalcogenide-based nanocomposites had characteristic peaks in the $100-500 \mathrm{~cm}^{-1}$ regions [30]. Some main peaks were not observed, because of the modification of the crystal lattice vibrations of the nanomaterial. The AFNSGT included four main peaks at 136.62, 259.13,391.54, and $585.26 \mathrm{~cm}^{-1}$, all assigned to the $\mathrm{TiO}_{2}$. The Raman band of anatase-structured $\mathrm{TiO}_{2}$ was obtained in the $100-700 \mathrm{~cm}^{-1}$ shift region, which included the $E_{g}, B_{1 g}$, and $A_{1 g}$ modes. The $E_{g}$ mode peak appeared at 136.62 and $585.26 \mathrm{~cm}^{-1}$, the $B_{1 \mathrm{~g}}$ mode peak at $391.54 \mathrm{~cm}^{-1}$, and the last one was the SEO peak at 259.13 $\mathrm{cm}^{-1}$, which indicates the motions of atoms. The characteristic peaks of graphene and the quaternary nanocomposites were not obtained in AFNSGT, because the symmetric motion of graphene was distorted and the peak intensity of $\mathrm{TiO}_{2}$ was sharp and strong. After we magnified the Raman peak of AFNSGT, the characteristic peaks of graphene were obtained at 1420.52 and $1534.85 \mathrm{~cm}^{-1}$ with low intensity.

The charge transfer and interactions between AFNS, $\mathrm{TiO}_{2}$, and Graphene were studied using a DRS, Photocurrent response, $\mathrm{PL}$, and EIS method. The band gap energy value of each nanocomposite was 
computed by UV-vis DRS, using Equation [2] [31]:

$\left[h v F\left(R_{\infty}\right)\right]^{1 / \mathrm{n}}=A\left(h v E_{g}\right)$

where $E_{\mathrm{g}}$ is the energy of the band gap, $F(R)(1 R)^{2} / 2 R$ is the Kubelka-Munk function, $A$ is the constant of proportionality, and $F(R)$ is the absorption coefficient, $h v=h c / \lambda$ is the energy of the incident photon.

All samples had a light response in the Vis-light region and near-UV light, as shown in Figure 7 (b). The calculated band gap of each nanocomposite was $2.34,2.24$, and $2.96 \mathrm{eV}$, which was lower than that of pure anatase $\mathrm{TiO}_{2}$, as shown in Figure 7 (a).

The quaternary nanocomposite had a visible-light response because of the band gap energy. After being combined with graphene, the band gap value was reduced. Graphene has good electron conductivity and mobility and can increase the separation of charge carriers. After being combined with anatase-structure $\mathrm{TiO}_{2}$, the band gap value increased from 2.24 to $2.96 \mathrm{eV}$. The pure anatase $\mathrm{TiO}_{2}$ has $3.20 \mathrm{eV}$ of band gap energy and had high catalytic activity with long-term stability but has fast electron-hole recombination with poor adsorption. Our obtained band gap value was lower than that of pure $\mathrm{TiO}_{2}$. Furthermore, asprepared -nanocomposite had a vis-light response with low band gap value.

The photocurrent response of all samples showed repeatable signals under six on-off cycles, as shown in Figure 7 (c). All nanocomposites had a prompt and stable photocurrent response for each cycle. The photocurrent response decayed in the dark-condition but recuperated again once the light was on within $30 \mathrm{~s}$.

The above procedure can be described in terms of the presence of charge transmission from the $\mathrm{VB}$ to the $\mathrm{CB}$ under the light radiation. The pure quaternary nanocomposite had a smaller current value $\left(3.95 \times 10^{-6} \mathrm{~mA} / \mathrm{cm}^{2}\right)$ in every cycle, which had low separation efficiency of the photo generated charge. AFNSG has efficient photo generated charges because of its good photocurrent response $\left(1.12 \times 10^{-5}\right.$ $\left.\mathrm{mA} / \mathrm{cm}^{2}\right)$; the graphene supports the charge separation and promotes the electron flow in the light-on state. AFNSGT showed a higher photocurrent value $\left(8.75 \times 10^{-6} \mathrm{~mA} / \mathrm{cm}^{2}\right)$ than did AFNS during six on-off cycles of light irradiation.

The final ternary photocatalyst can show better catalytic activity than that of the pure quaternary nanocomposite because of its efficient separation of photogenerated charges and interfacial contact among $\mathrm{AgFeNi}_{2} \mathrm{~S}_{4}$, Graphene, and $\mathrm{TiO}_{2}$.

The charge separation capability of the $\mathrm{AgFeNi}_{2} \mathrm{~S}_{4}-\mathrm{Graphene}^{-\mathrm{TiO}_{2}}$ was analyzed by the PL method. The intensity of PL depends on the recombination rate of the electron-hole pairs, and a decrease in PL intensity indicates the long lifetime of the charge carrier among the semiconductors. All photocatalysts showed a light response under the $514 \mathrm{~nm}$ laser, as shown in Figure 7 (d). The emission peaks of samples were appeared in the 550-650 nm range which related to the visible light region. In the PL 
spectra, two sharp emission peaks appeared at 552.99 and $560.37 \mathrm{~nm}$ wavelength regions. Additionally, the pure AFNS had a low-intensity wide emission peak in the $604.66 \mathrm{~nm}$ area, but the peak intensity was reduced in AFNSGT.

The emission peak of the metal-based composite was classified in two sector: (1) UV emission (NBE), (2) Visible emission (DF defect) [32]. The PL intensity of pure AFNS was high because of rapid charge recombination. After being combined with carbon-material and $\mathrm{TiO}_{2}$, the $\mathrm{PL}$ intensity was reduced because of efficient interfacial contact between each part, which bolster the charge carriers transmission. The low PL intensity with the recombination rate of electron and holes, which is related to rapid conversion from $\mathrm{CO}_{2}$ into hydrocarbon fuel.

Figure 7 (e) shows the electrochemical impedance spectroscopy (EIS) of all samples; the EIS profile is identical to the charge transmit resistance across the electrode/electrolyte. The wide semicircle profile can confirm the poor charge carrier with low conductivity. Conversely, the small semi-circle can explain the high conductivity with an effective charge carrier, which can confirm the high catalytic performance of the photocatalyst. Figure 8 (e) shows the Nyquist plot of all samples at room temperature for the frequency range $5 \mathrm{mHz}$ and $1 \mathrm{mHz}$ with half-cell. The AFNSG sample had a smaller semicircle than did the pure AFNS and AFNSGT. The size of the semicircle depends on the chemical composition and interconnection of each AFNS, Graphene, and $\mathrm{TiO}_{2}$. Graphene had a small semicircle profile, because its high electrical conductivity can sustain the conductivity of the quaternary chalcogenide nanocomposite. In addition, the semicircular profile of the AFNSGT ternary nanocomposite is located between AFNS and AFNSG, depending on the electrical conductivity of AFNS, graphene, and $\mathrm{TiO}_{2}$.

A NiS-based or quantum dot united with carbon or a semiconductor photocatalyst is mostly used for $\mathrm{H}_{2}$ evolution [33-35]. According to a published paper [36-38], some research papers reported on the NiSbased photocatalyst used for $\mathrm{CO}_{2}$ reduction under light illumination. Generally, a one-spot and seedmediated hydrothermal method and a sol-gel method are used to prepare NiS photocatalysts [1, 2]. In addition, the binary photocatalyst showed a high charge-transfer property and good conductivity. All the analysis results confirmed that the prepared binary photocatalyst can show high stability and photoactivity for $\mathrm{CO}_{2}$ reduction. According to all the electrochemical analysis result, the AFNSGT ternary nanocomposite had successful formation and a high interconnection with highly efficient charge transfer, and suppression of the photogenerated $\mathrm{e}^{-}$and $\mathrm{h}^{+}$recombination rate; all those factors can upgrade the photocatalytic reduction of $\mathrm{CO}_{2}$ into hydrocarbon products. Compared to the electrochemical result of binary nanocomposites, the ternary nanocomposite showed a low result, but the combination of anatase$\mathrm{TiO}_{2}$ with graphene and metal nanocomposite had high photocatalytic activity. Also, the combination of 2D graphene and $\mathrm{TiO}_{2}$ with a metal nanocomposite had more intimate contact, superior electronic coupling, and a more sensitive photosensitizer, which can lead to better $\mathrm{CO}_{2}$ reduction under light irradiation [39]. Based on the results of the above studies and the results of our study, we assume that the ternary nanocomposite has high photocatalytic activity for $\mathrm{CO}_{2}$ reduction. 


\subsection{Photocatalytic performance and reduction of $\mathrm{CO}_{2}$}

The final ternary $\mathrm{AgFeNi}{ }_{2} \mathrm{~S}_{4}-\mathrm{Graphene}^{-} \mathrm{TiO}_{2}$ was used for the photocatalytic reduction of $\mathrm{CO}_{2}$ with two different electron-donor scavengers $\left(\mathrm{Na}_{2} \mathrm{SO}_{3}\right.$ and $\left.\mathrm{Na}_{2} \mathrm{~S}\right)$. Figure 8 shows the quantification of the final methanol yield. The final concentration of methanol was analyzed by the "Quantitative Analysis of Alcohol" using $\mathrm{CrO}_{3}$ as a strong oxide agent. During the experiment, the final methanol was oxides, and the oxidation state of $\mathrm{CrO} 3$ decreased. Then, the color of the base solution was changed. Briefly, as the methanol concentration increases, the oxidation state of $\mathrm{CrO}_{3}$ decreases, and the color of the base solution changes accordingly.

Figure 8 (a) and (c) show the final product yield with different amounts of $\mathrm{Na}_{2} \mathrm{SO}_{3}$ under light irradiation. The final product yield increased when the amount of electron donors increased from 0.2 to $0.6 \mathrm{~g}$. The methanol yields increased from 4.05 to $6.25 \%$ when the scavenger amount increased $(0.2,0.4$, and $0.6 \mathrm{~g})$ after 48 hours under vis-light irradiation.

With $0.2 \mathrm{~g}$ of a scavenger, the final product yield was $0.56,2.01,3.74$, and $4.05 \%$, while using a $0.4 \mathrm{~g}$ of a scavenger, the yield was $1.94,2.16,2.74$, and $5.19 \%$ under the visible light irradiation. The highest methanol yield was found when using $0.6 \mathrm{~g}$ of $\mathrm{Na}_{2} \mathrm{SO}_{3}$, and the methanol yield was $1.80,2.50,4.53$, and $6.25 \%$ after 12 to 48 hours under the vis-light. Under the UV-light, the methanol yield was $0.54,2.95,4.77$, and $6.03 \%$ with $0.2 \mathrm{~g}$, and the yield was $0.85,2.13,5.55$, and $7.17 \%$ with $0.4 \mathrm{~g} \mathrm{of} \mathrm{Na}_{2} \mathrm{SO}_{3}$. When using a $0.6 \mathrm{~g}$ scavenger, the final product yield was $1.17,2.24,6.80$, and $8.62 \%$ after 12 to 48 hours under light irradiation. The final hydrocarbon fuel amount increased with various quotas of scavengers under the UVlight irradiation, because of the photon energy of each light source.

To determine the effect of the $\mathrm{Na}_{2} \mathrm{SO}_{3}$ scavenger, we used another scavenger $\left(\mathrm{Na}_{2} \mathrm{~S}\right)$ under the same condition. Figure 8 (b) and (d) show the methanol yield with different quotas of $\mathrm{Na}_{2} \mathrm{~S}$ scavenger under illumination. The final product yield was $0.54,1.00,2.07$, and $3.59 \%$ with low amount of scavenger, and the yield was $0.55,1.72,2.29$ and $4.97 \%$ with $0.4 \mathrm{~g}$ of $\mathrm{Na}_{2} \mathrm{~S}$. When using $0.6 \mathrm{~g}$ of $\mathrm{Na}_{2} \mathrm{~S}$, the final product yield was $0.48,2.59,3.34$ and $5.92 \%$ after 12 to 48 hours under the vis-light. After $48 \mathrm{~h}$, the maximum alcohol yields were determined at 5.09, 6.03, and $7.23 \%$ under UV light, and different amounts of $\mathrm{Na}_{2} \mathrm{~S}$ electron donor suppliers were used during the experiment.

The stability and reusability are the main factors that define the sturdiness of a photocatalyst in practical application. In the recycling test, the photocatalyst (AFNSGT) was used six times ( $288 \mathrm{~h}$ ) under light irradiation with two-different scavengers $(0.6 \mathrm{~g})$ in $\mathrm{CO}_{2}$ evolution. The ternary photocatalyst was very sturdy during six recycles with no significant deactivation towards methanol production, as shown in Figure 9. According to the recycling test, the ternary photocatalyst can be considered for generating solar fuels in a practical application.

From the results of the above experiments, it can be concluded that the best $\mathrm{CO}_{2}$ reduction was obtained in the UV light region, because it can supply the efficient photon energy which can activate the 
photocatalyst. A scavenger (sodium carbonate and sodium sulfide) with a cyclic electron donor/supplier can boost the photoactivity of a graphene-based ternary photocatalyst because it allows that $\mathrm{CO}_{2}$ combined with water. More specifically, there are two reasons: (i) an increase in the amount of dissolved $\mathrm{CO}_{2}$ (ii) and reduction of the recombination of hole-electron pairs, leading to a longer decay time of surface electrons and facilitation of $\mathrm{CO}_{2}$ reduction. To identify the presence of the final products and semi-product, the FTIR technique was used. The final methanol (after 1 and 6-cycles) and commercial methanol solution were used in this FTIR analysis. The FTIR spectrum of methanol shown in Figure 10, consisted of four characteristic peaks located at theoretical peak region and all data keys are summarized in Table 1. The FTIR spectrum of all samples was exhibited in a range of $800-4000 \mathrm{~cm}^{-1}$. The peak location and intensity of the reference and methanol products were the same which confirms that the ternary photocatalyst reduced the $\mathrm{CO}_{2}$ into methanol. During the test, the semi-product was withdrawn from the reactor and analyzed by FTIR. This result suggests that the chemical structure of $\mathrm{CO}_{2}$ had changed, and it confirmed that carbon dioxide can be reduced to methanol.

All used photocatalyst was collected, rinsed with water, and dried at $100^{\circ} \mathrm{C}$ in an oven. The crystal structure of the photocatalyst before and after the experiment analyzed via XRD measurement. There is no significant change obtained from the XRD pattern and this result confirmed the stability of the photocatalyst. XRD pattern of the samples displayed in Figure 11. The XRD pattern of the photocatalyst before and after the experiment confirmed the stability and reusability of the material. Currently, the research paper on the quaternary chalcogenide-based nanocomposites for $\mathrm{CO}_{2}$ reduction has not been published. There are several ternary chalcogenide photocatalysts, for $\mathrm{CO}_{2}$ reduction such as $\mathrm{ZnO} / \mathrm{ZnSe}$ [40], $\mathrm{CeO}_{3} / \mathrm{ZnInS}_{2}$ [41] and $\mathrm{CuInS}_{2}-\mathrm{TiO}_{2}$ heterojunctions [42]. The $\mathrm{AgFeNi}_{2} \mathrm{~S}_{4}-\mathrm{Graphene}^{-\mathrm{TiO}_{2}}$ exhibits higher photocatalytic $\mathrm{CO}_{2}$ conversion activities than did the other ternary chalcogenide photocatalysts. Therefore, noble-metal joined quaternary chalcogenide catalyst can still achieve high-efficiency $\mathrm{CO}_{2}$ reduction.

The pathway of $\mathrm{CO}_{2}$ reduction was described in Scheme 1 and chemical reaction was suggested in below part. The reduction process of $\mathrm{CO}_{2}$ to methanol is unique due to the reaction pathways. In general, the reduction of $\mathrm{CO}_{2}$ needs more negative potential level in conduction band, the water oxidation needs more positive level in valence band, thereby increasing the number of protons and enhancing the reduction of carbon dioxide. Under the vis/UV light irradiation, both $\mathrm{AgFeNi}_{2} \mathrm{~S}_{4}$ and $\mathrm{TiO}_{2}$ were absorbs the photon's energy, the electron can be excited from VB to CB. Graphene can accelerate the charge carrier between AFNS and $\mathrm{TiO}_{2}$ and suppress the recombination of charges. 


$$
\begin{aligned}
& \mathrm{TiO}_{2}+\mathrm{hv} \rightarrow \mathrm{e}^{-}\left(\mathrm{TiO}_{2}\right)+\mathrm{h}^{+}\left(\mathrm{TiO}_{2}\right) \\
& \mathrm{AgFeNi}_{2} \mathrm{~S}_{4}+\mathrm{hv} \rightarrow \mathrm{e}^{-}\left(\mathrm{AgFeNi}_{2} \mathrm{~S}_{4}\right)+\mathbf{h}^{+}\left(\mathrm{AgFeNi}_{2} \mathrm{~S}_{4}\right) \\
& \mathbf{e}^{-}\left(\mathrm{TiO}_{2}\right)+\text { Graphene } \mathrm{TiO}_{2}+\mathbf{e}^{-}(\text {Graphene })
\end{aligned}
$$

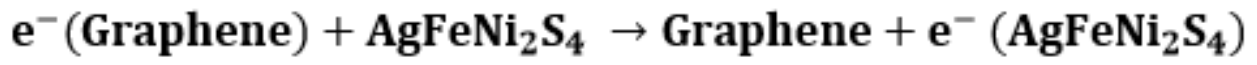

$$
\begin{aligned}
& \mathbf{H}_{2} \mathbf{O}+\mathbf{h}^{+} \rightarrow \mathbf{H}^{+}+\mathbf{O H}^{-} \\
& \mathrm{CO}_{2}+\mathrm{e}^{-} \rightarrow \mathrm{CO}_{2}^{--} \\
& \mathrm{CO}_{2}^{+}+2 \mathrm{H}^{\boxplus}+2 \mathrm{e}^{-}=\mathrm{HCO}_{2} \mathrm{H} \quad \text { (Formic acid) } \\
& \mathrm{CO}_{2}+2 \mathrm{H}^{+}+2 \mathrm{e}^{-} \rightarrow \mathrm{CO}+\mathrm{H}_{2} \mathrm{O} \text { (Carbon monoxide) } \\
& \mathrm{CO}_{2}+4 \mathrm{H}^{+}+4 \mathrm{e}^{-} \rightarrow \mathrm{HCHO}+\mathrm{H}_{2} \mathrm{O} \text { (Formaldehyde) } \\
& \mathrm{CO}_{2}+6 \mathrm{H}^{+}+6 \mathrm{e}^{-} \rightarrow \mathrm{CH}_{3} \mathrm{OH}+\mathrm{H}_{2} \mathrm{O} \text { (Methanol) }
\end{aligned}
$$

Eqs. (1) (4) describe the activation of $\mathrm{AgFeNi}_{2} \mathrm{~S}_{4}, \mathrm{TiO}_{2}$, and graphene, which enables them to produce the photoexcited electron-hole pairs. Eqs. (6-9) describe the redox reaction, where the holes are used for oxidation and electrons are used for the reduction process. The positive-charged holes reacted with water to form hydrogen, and the hydrogen source is favorably activating the formation of methanol. Meanwhile, the purged $\mathrm{CO}_{2}$ was adsorbed on photocatalyst surface, thereby the photo-excited electrons on the surface can reduce/convert the $\mathrm{CO}_{2}$ into methanol. The conversion of $\mathrm{CO}_{2}$ into $\mathrm{CH}_{3} \mathrm{OH}$ required $6 \mathrm{e}^{-} / 6 \mathrm{H}^{+}$.

\section{Conclusions}

In summary, we successfully synthesized the graphene-based ternary photocatalyst containing a chalcogenide nanocomposite $\left(\mathrm{AgFeNi}_{2} \mathrm{~S}_{4}\right)$ by a modified solvothermal method. The as-prepared samples analyzed with some spectroscopic techniques for the confirmation of catalytic activity of the photocatalyst for the $\mathrm{CO}_{2}$ reduction into hydrocarbon fuels with two different scavengers. The final photocatalyst showed high conversion efficiency because of efficient separation of photogenerated charge $\left(\mathrm{e}^{-}\right.$and $\mathrm{h}^{+}$) and strong interfacial contact among $\mathrm{AgFeNi}_{2} \mathrm{~S}_{4}, \mathrm{Graphene}$, and $\mathrm{TiO}_{2}$. The methanol yield was 6.25 and $8.62 \%$ under the visible and UV light irradiation when using $0.6 \mathrm{~g}$ of the $\mathrm{Na}_{2} \mathrm{SO}_{3}$ scavenger. In addition, the yield was 5.92 and $7.23 \%$ when using the same amount of $\mathrm{Na}_{2} \mathrm{~S}$ scavenger. The two scavengers that provided the different values of cyclic electron donor/supplier can boost the photoactivity and it allow the $\mathrm{CO}_{2}$ to be combined with water. The reusability of the ternary catalyst was high after six cycles, which confirmed that the as-prepared catalyst can be useful for the practical 
applications. In this work, we used the quaternary chalcogenide nanocomposite loaded graphene-based photocatalyst to support the benefits of a heterogeneous system and developed the evolution rate of $\mathrm{CO}_{2}$ into liquid methanol $\left(\mathrm{CH}_{3} \mathrm{OH}\right)$.

\section{References}

1. Hao, Q., Rui-Tang, G., Xing-Yu, L., Xu, S., Zhong-Yi, W., Jun-Ying, T., Wei-Guo, P. OD NiS 2 quantum dots modified 2D g- $\mathrm{C}_{3} \mathrm{~N}_{4}$ for efficient photocatalytic $\mathrm{CO}_{2}$ Colloids and Surfaces $A$, (2020), 600, 124912.

2. Jae, H. L., Sung-II, K., Sun-M. P., Misook, K. A p-n heterojunction NiS-sensitized TiO2 photocatalytic system for efficient photoreduction of carbon dioxide to methane. Ceramics International, (2017), 43, 1768-1774.

3. Ali, A., Nguyen, D. C. T., Cho, K. Y., Oh, W. C. A simple ultrasonic-synthetic route of $\mathrm{Cu}_{2} \mathrm{Se}$-graphene$\mathrm{TiO}_{2}$ ternary composites for carbon dioxide conversion processes, Fullerenes, Nanotubes and Carbon Nanostructures, (2018), 26:12, 827-836.

4. Min, Y., He, G., Xu, Q., Chen, Y. Dual-functional $\mathrm{MoS}_{2}$ sheet-modified CdS branch-like heterostructures with increased photostability and photocatalytic activity, J Mater Chem A, (2014), 2, 2578-2584.

5. Devi, S., Korake, P., Achary, S.N., Gupta. N.M. Genesis of increased photoactivity of $\mathrm{CdS} / \mathrm{Ni}_{\mathrm{x}}$ nanocomposites for visible-light-driven splitting of water, Int J Hydrogen Energy, (2014), 39, 19424-19433.

6. Zhang, W., Xu, R. Surface engineered active photocatalysts without noble metals: CuS-ZnxCd1-xS nanospheres by one-step synthesis, Int J Hydrogen Energy, (2009), 34, 8495-8503.

7. Zong, X., Han, J., Ma, G., Yan, H., Wu, G., Li, C. Photocatalytic $\mathrm{H}_{2}$ evolution on CdS loaded with $\mathrm{WS}_{2}$ as cocatalyst under visible light irradiation, J Phys Chem C, (2011), 115, 12202-12208.

8. Santhosh, K. M. C., Pradeep, B. Electrical properties of silver selenide thin films prepared by reactive evaporation, Bull Mater Sci., (2002), 25, 407-411.

9. Ya, N.L., Yan, L., Long-long, Q., Xiao, T.W., Jian, W., Cheng, W.W. Excellent photocatalytic performance from NiS decorated $\mathrm{TiO}_{2}$ nanoflowers with exposed $\{001\}$ facets, Materials Research Bulletin, (2020), $130,110945$.

10. Xuan, W., Hao, D., Sijia, S., Han, Z., Run, Z., Yangzi, L., Yu, L., Jie, W. Preparation of a temperaturesensitive superhydrophobic self-cleaning $\mathrm{SiO}_{2}-\mathrm{TiO}_{2} @ P D M S$ coating with photocatalytic activity, Coat. Tech, (2021), 9, 126853.

11. Tian, H., Shen, K., Hu, X., Qiao, L., \& Zheng, W N. S co-doped graphene quantum dots-graphene-TiO 2 nanotubes composite with increased photocatalytic activity, Journal of Alloys and Compounds, (2017), 691, 369-377.

12. Choi, K.H., Park, S.Y., Park, B.J., Jung, J.S. Recyclable Ag-coated $\mathrm{Fe}_{3} \mathrm{O}_{4} @ \mathrm{TiO}_{2}$ for efficient photocatalytic oxidation of chlorophenol, Coat. Tech., 320 (2017), pp. 240-245 
13. Zhang, P., Wang, T., Gong, J. Mechanistic Understanding of the Plasmonic Enhancement for Solar Water Splitting, Mater., 27 (2015), pp. 5328-5342

14. Eda, G., Fanchini, G., Chhowalla. M. Large-area ultrathin films of reduced graphene oxide as a transparent and flexible electronic material, Nature Nanotechnology, (2008), 3, 270-274.

15. Stankovich, S., Dikin, D.A., Dommett, G.H.B., Kohlhaas, K.M., Zimney, E.J., Stach, E.A., Piner, R.D., Nguyen, S.T., Ruoff, R.S. Graphene-based composite materials. Nature, (2006), 442, 282-286.

16. Tian, H., Wan, C., Xue, X., Hu, X., Wang, X. Effective Electron Transfer Pathway of the Ternary $\mathrm{TiO}_{2} / \mathrm{RGO} / \mathrm{Ag}$ Nanocomposite with Increased Photocatalytic Activity under Visible Light, Catalysts, (2017), 7,

17. Huang, H., Liu, K., Zhang, Y., Chen, K., Zhang, Y., Tian, N. Tunable 3D hierarchical graphene-BiOI nanoarchitectures: Their in-situ preparation, and highly improved photocatalytic performance and photoelectrochemical properties under visible light irradiation, RSC Adv., 4 (2014), pp. 49386-49394

18. Oh, W.C., Zhang, F.J. Preparation, and characterization of graphene oxide reduced from a mild chemical method, Asian J. Chem. 23 2011, 875.

19. Yan, Y., Sun, S., Song, Y., Yan, X., Guan, W., Liu, X., Shi, W. Microwave-assisted in situ synthesis of reduced graphene oxide- $\mathrm{BiVO}_{4}$ composite photocatalysts and their increased photocatalytic performance for the degradation of ciprofloxacin, J. Hazard. Mater., (2013), 250, 106-114.

20. Rajendran, R., Shrestha, L.K., Minami, K., Subramanian, M., Jayavel, R., Ariga, K, Dimensionally integrated nanoarchitectonics for a novel composite from OD, 1D, and 2D nanomaterials: $\mathrm{RGO} / \mathrm{CNT} / \mathrm{CeO}_{2}$ ternary nanocomposites with electrochemical performance, J. Mater. Chem. A, 2 (2014), pp. 18480-18487.

21. Zambaga, O., Oh, W.C. Photocatalytic $\mathrm{CO}_{2}$ reduction with Graphene-based semiconductor, Journal of Multifunctional Materials and Photoscience, 10 (2019), pp. 127-140.

22. Zambaga, O., Kwang Y.C., Oh, W.C. Novel Micro and Nanostructure of AgCulnS ${ }_{2}-G_{r a p h e n e-T_{2}}$ Ternary Composite for Photocatalytic $\mathrm{CO}_{2}$ Reduction for Methanol Fuel, ACS Omega, 5 (2020), 26389-26401.

23. Gondal, M.A., Suliman M.A., Dastageer, M.A., Gaik-Khuan Chau., Basheer, C., Dan Yang., Suwaiyan, A. Visible Light Photocatalytic Degradation of Herbicide (Atrazine) using Surface Plasmon Resonance Induced in Mesoporous $\mathrm{AgWO}_{3} / \mathrm{SBA}-15$ Composite, Journal of Molecular Catalysis A: Chemical, (2016), 425, 208-216.

24. Hongliang, P., Zaiyong, M., Shijun, L., Huagen, L., Lijun, Y., Fan, L., Huiyu, S., Yiliang, Z., Bingqing, Z., High Performance Fe- and N- Doped Carbon Catalyst with Graphene Structure for Oxygen Reduction. Scientific Reports, (2013) 3(1).

25. Yang, G., Liwei, M., Wutao, W., Shizhong, C., Zhi, Z., Hongwei, H., Weihua, C. Double Metal lons Synergistic Effect in Hierarchical Multiple Sulfide Microflowers for Increased Supercapacitor Performance, ACS Applied Materials \& Interfaces, (2015), 7(7), 4311-4319. 
26. Diptiman, D., Md. Estak, A., Sumit, M., Biswajit, M., Shyamal, K. S. Amorphous molybdenum sulfide quantum dots: an efficient hydrogen evolution electrocatalyst in neutral medium, Journal of Materials Chemistry A, (2016), 40, 15486-15493.

27. Hui, L., Shuang, , Zhiling, Z., Xiaonan, Ali, A., Nguyen, D. C. T., Cho, K. Y., Oh, W. C. A simple ultrasonicsynthetic route of $\mathrm{Cu}_{2} \mathrm{Se}$-graphene- $\mathrm{TiO}_{2}$ ternary composites for carbon dioxide conversion processes, Fullerenes, Nanotubes and Carbon Nanostructures., (2018), 26:12, 827-836.

28. Demri, B., Muster, D. XPS study of some calcium compounds, Journal of Materials Processing Technology, (1995), 55, 311-314.

29. Hussein, Z., Ming, H., Ang, Moses, O. T. Ta/ $\mathrm{TiO}_{2}$-and $\mathrm{Nb} / \mathrm{TiO}_{2}$-Mixed Oxides as Efficient Solar Photocatalysts: Preparation, Characterization, and Photocatalytic Activity, International Journal of Photoenergy, (2012), 1-9.

30. Pandiaraman, M., Soundararajan, N. Micro-Raman studies on thermally evaporated $\mathrm{Ag}_{2}$ Se thin films, Journal of Theoretical and Applied Physics., (2012), 6:7.

31. Pyrgiotakis, G., Wolfgang, S. M. X-Ray Photoelectron Spectroscopy of Anatase-TiO ${ }_{2}$ Coated Carbon Nanotubes, Solid State Phenomena., (2010), 162, 163-177.

32. Kumar, S., Bhunia, S., Singh, J., Ojha, A. K. Absence of room temperature ferromagnetism in Fe stabilized $\mathrm{ZrO}_{2}$ nanostructures and effect of Fe doping on its structural, optical and luminescence properties, Alloy. Compd., (2015), 649, 348-356.

33. Zhou, X., Sun, H., Zhang, H., Tu, W. One-pot hydrothermal synthesis of CdS/NiS photocatalyst for high $\mathrm{H}_{2}$ evolution from water under visible light, Int J Hydrogen Energy, (2017), 42, 11199-11205.

34. Wang, B., Ding, Y., Deng, Z., Li, Z. Rational design of ternary NiS/CQDs/Znln ${ }_{2} S_{4}$ nanocomposites as efficient noble-metal-free photocatalyst for hydrogen evolution under visible light, J. Catal, (2019), 40, 335-342.

35. Li, G., Sun, Y., Zhang, Q., Gao, Z., Sun, W., Zhou, X. Ag quantum dots modified hierarchically porous and defective $\mathrm{TiO}_{2}$ nanoparticles for improved photocatalytic $\mathrm{CO}_{2}$ reduction, Chem. Eng. J, (2021), 410, 128397.

36. Tang, J.Y., Guo, R.T., Zhou, W.G., Huang, C.Y., Pan W.G. Ball-flower like NiO/g- $\mathrm{C}_{3} \mathrm{~N}_{4}$ heterojunction for efficient visible light photocatalytic $\mathrm{CO}_{2}$ reduction, Catal. B: Environ., (2018), 237, 802-810.

37. Chen, F., Yang, H., Wang, X., Yu, H. Facile synthesis and enhanced photocatalytic $\mathrm{H}_{2}$-evolution performance of $\mathrm{NiS}_{2}$-modified g- $\mathrm{C}_{3} \mathrm{~N}_{4}$ photocatalysts, J. Catal., (2017), 38, 296-304.

38. Qin, H., Guo, R.T., Liu, X.Y., Pan, W.G., Wang, Z.Y., Shi, X., Tang, J.Y., Huang, C.Y. Z-scheme $\mathrm{MoS}_{2}$ /g$\mathrm{C}_{3} \mathrm{~N}_{4}$ heterojunction for efficient visible light photocatalytic $\mathrm{CO}_{2}$ reduction, Dalton Trans., (2018), 47, 15155-15163

39. Xie, S., Zhang, Q., Liu, G., Wang, Y. Photocatalytic and photoelectrocatalytic reduction of $\mathrm{CO}_{2}$ using heterogeneous catalysts with controlled nanostructures, Commun., (2015), 15, 1-24. 
40. Shuangfang, Z., Xiaohong Y., Yinan, Z. Increased photocatalytic reduction of $\mathrm{CO}_{2}$ to methanol by ZnO nanoparticles deposited on ZnSe nanosheet, Phys. Lett, 693 2018, 170-175.

41. Chao, Y., Qin, L., Yang, X., Kangle, Lv., Mei, L. Increased visible-light photocatalytic $\mathrm{CO}_{2}$ reduction performance of $\mathrm{ZnIn}_{2} \mathrm{~S}_{4}$ microspheres by using $\mathrm{CeO}_{2}$ as cocatalyst, Surf. Sci, 464 (15) 2019, 388395.

42. Feiyan, X., Jianjun, Z., Bicheng, Z., Jiaguo, $\mathrm{Y}$., Jingsan, $\mathrm{X}$. Culn $\mathrm{S}_{2}$ sensitized $\mathrm{TiO}_{2}$ hybrid nanofibers for improved photocatalytic $\mathrm{CO}_{2}$ reduction, Catal. B: Environ, 230 (15) 2018, 194-202.

\section{Tables}

Table 1. Characteristic vibrational group of the final-product from the FTIR measurement.

\begin{tabular}{|lllll|}
\hline № & Vibrational state & Mode & Experimental $\left(\mathrm{cm}^{-1}\right)$ & Theoretical $\left(\mathrm{cm}^{-1}\right)$ \\
\hline 1 & Hydroxyl group & $(\mathrm{O}-\mathrm{H})$ & $3295.34 \mathrm{~cm}^{-1}$ & $3400-3300 \mathrm{~cm}^{-1}$ \\
\hline 2 & Alcohol group & $\mathrm{C}-\mathrm{O}-\mathrm{H}$ & $1277.38 \mathrm{~cm}^{-1}$ & $1440-1220 \mathrm{~cm}^{-1}$ \\
\hline 3 & Methyl group & (C-H) in $\left(\mathrm{CH}_{3}\right) \delta$ & $1639.71 \mathrm{~cm}^{-1}$ & $1450 \mathrm{~cm}^{-1}$ \\
\hline 4 & Carbonyl group & C-O & $1015.54 \mathrm{~m}^{-1}$ & $1300-1000 \mathrm{~cm}^{-1}$ \\
\hline
\end{tabular}

\section{Figures}




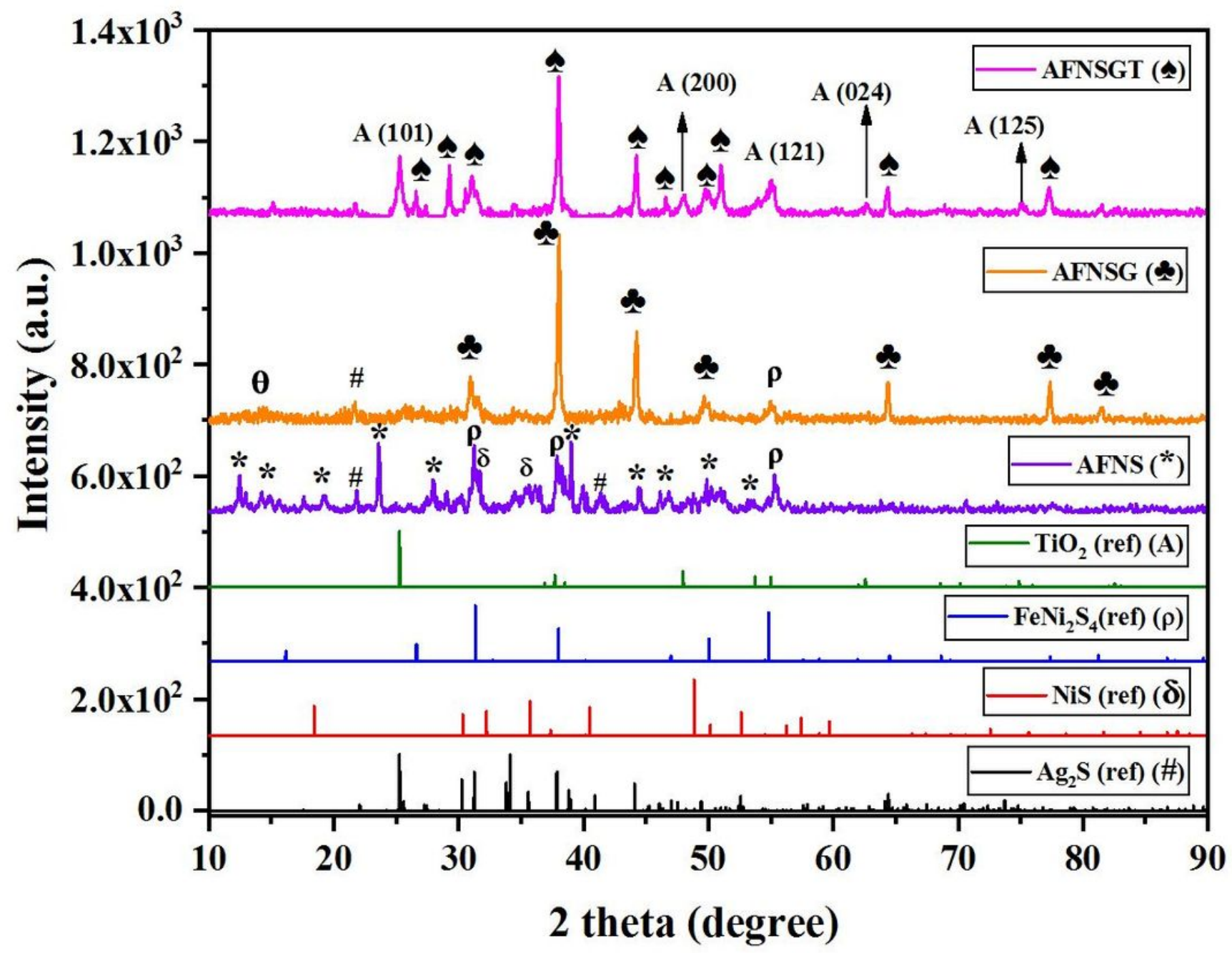

Figure 1

XRD pattern of synthesized AgFeNi2S4 ,AgFeNi2S4-Graphene, and AgFeNi2S4-Graphene-TiO2 nanocomposites. 

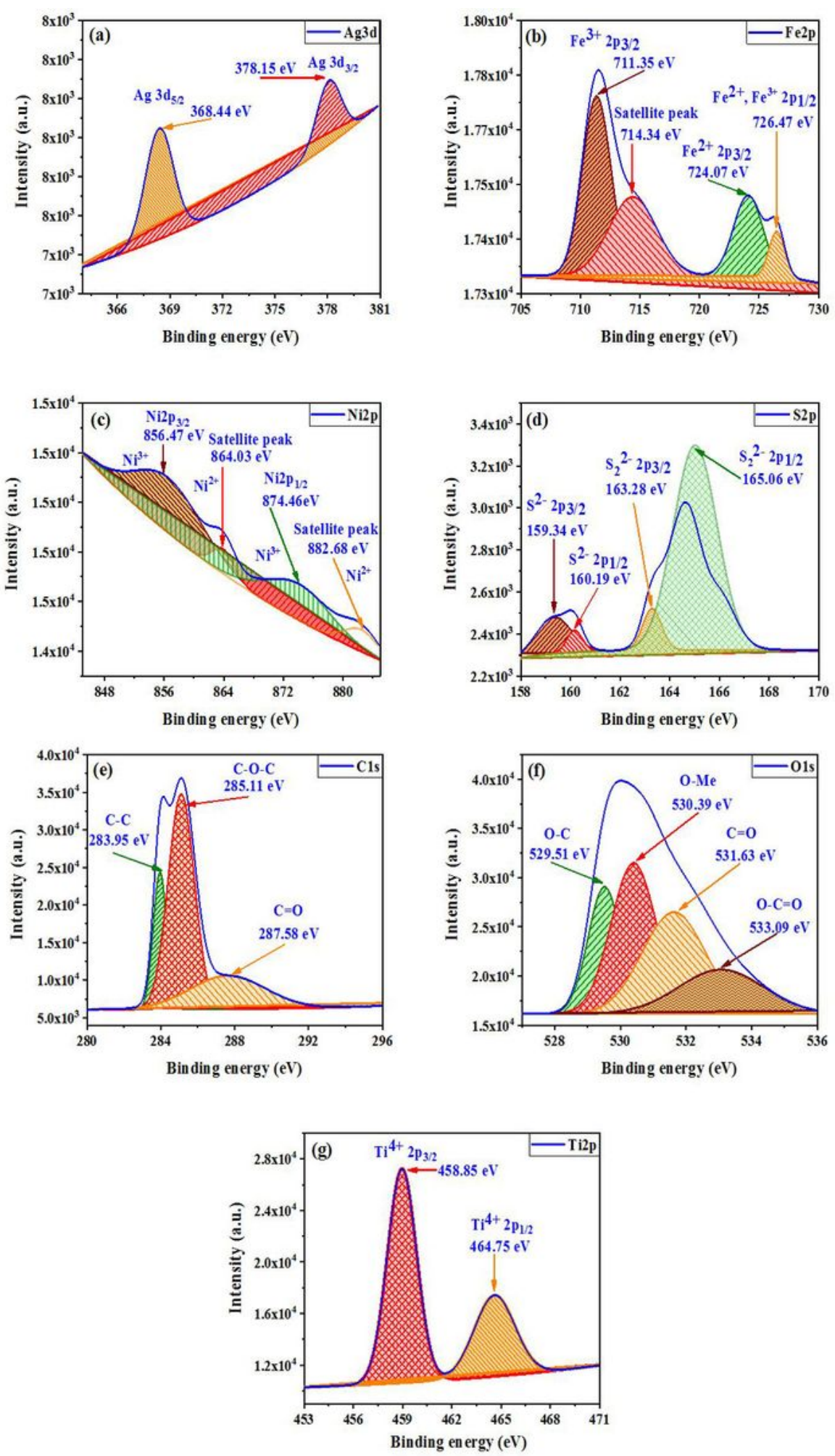

Figure 2

XPS survey spectra and the high-resolution XPS spectra of AgFeNi2S4-Graphene-TiO2 (synthesized by a solvothermal method), (a) Ag3d, (b) Fe2p, (c) Ni2p, (d) S2p, (e) C1s, (f) 01s, and (g) Ti2p. 

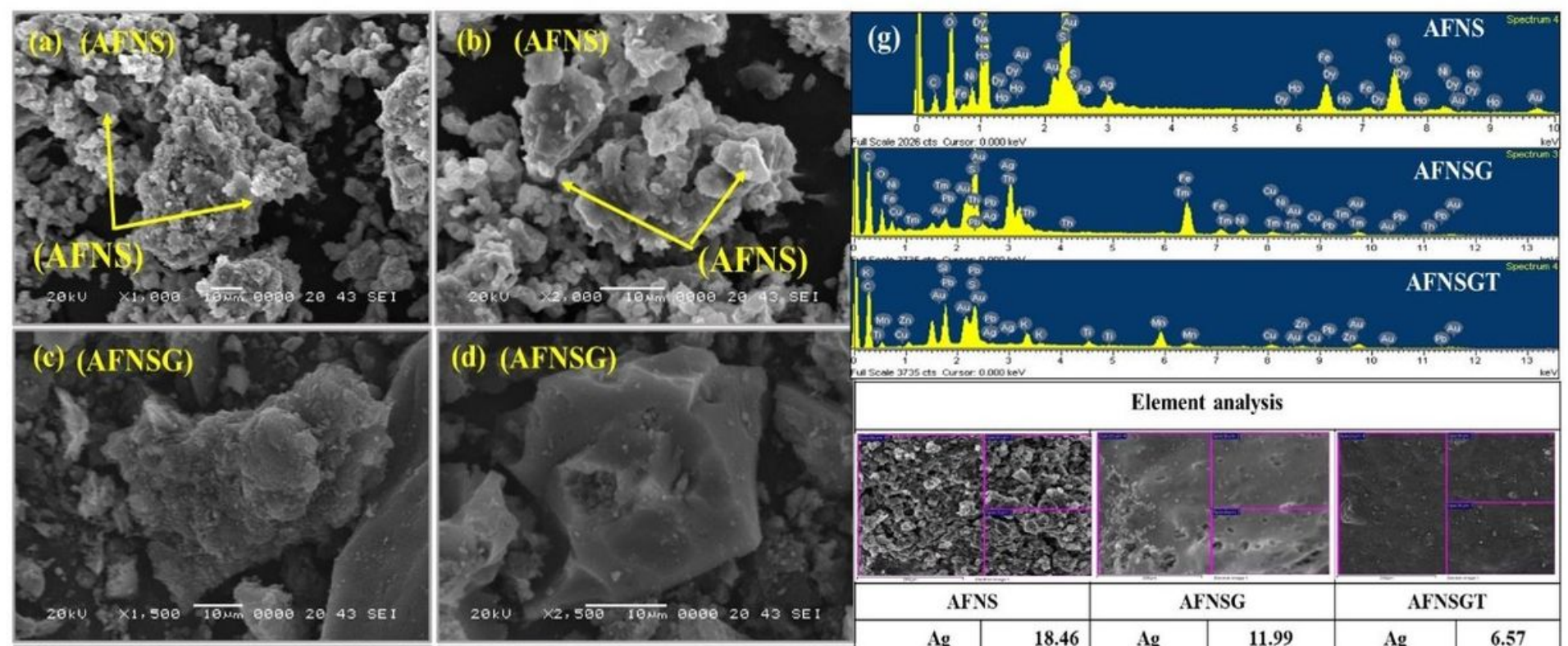

\begin{tabular}{|c|c|c|c|c|c|}
\hline \multicolumn{6}{|c|}{ Element analysis } \\
\hline \multicolumn{2}{|c|}{ 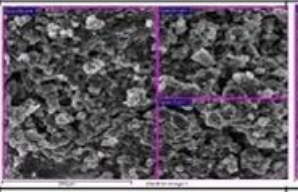 } & & & & \\
\hline \multicolumn{2}{|c|}{ AFNS } & \multicolumn{2}{|c|}{ AFNSG } & \multicolumn{2}{|c|}{ AFNSGT } \\
\hline \multirow[t]{2}{*}{ Ag } & \multirow[t]{2}{*}{18.46} & \multirow[t]{2}{*}{ Ag } & 11.99 & $\mathrm{Ag}$ & 6.57 \\
\hline & & & & $\mathbf{F}$ & 9.94 \\
\hline \multirow[t]{2}{*}{$\mathrm{Fe}$} & \multirow[t]{2}{*}{29.01} & $\mathrm{re}$ & 10.18 & $\mathbf{N i}$ & 7.27 \\
\hline & & $\mathrm{Ni}$ & 8.84 & S & 9.37 \\
\hline $\mathbf{N i}$ & 22.04 & $\mathrm{~S}$ & 7.37 & $\mathrm{C}$ & 22.23 \\
\hline \multirow[t]{2}{*}{ S } & \multirow{2}{*}{27.09} & $\mathrm{C}$ & 41.33 & o & 27.34 \\
\hline & & o & 20.29 & $T$ & 17.28 \\
\hline Total & 100 & Total & 100 & Total & 100 \\
\hline
\end{tabular}
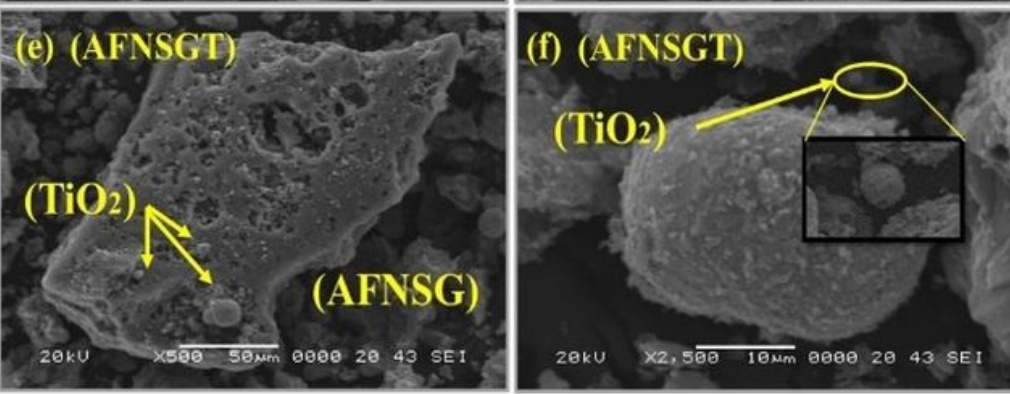

\section{Figure 3}

SEM image; (a-b) AgFeNi2S4, (c-d) AgFeNi2S4-Graphene, (e-f) AgFeNi2S4-Graphene-TiO2, and (g) EDX analysis. 

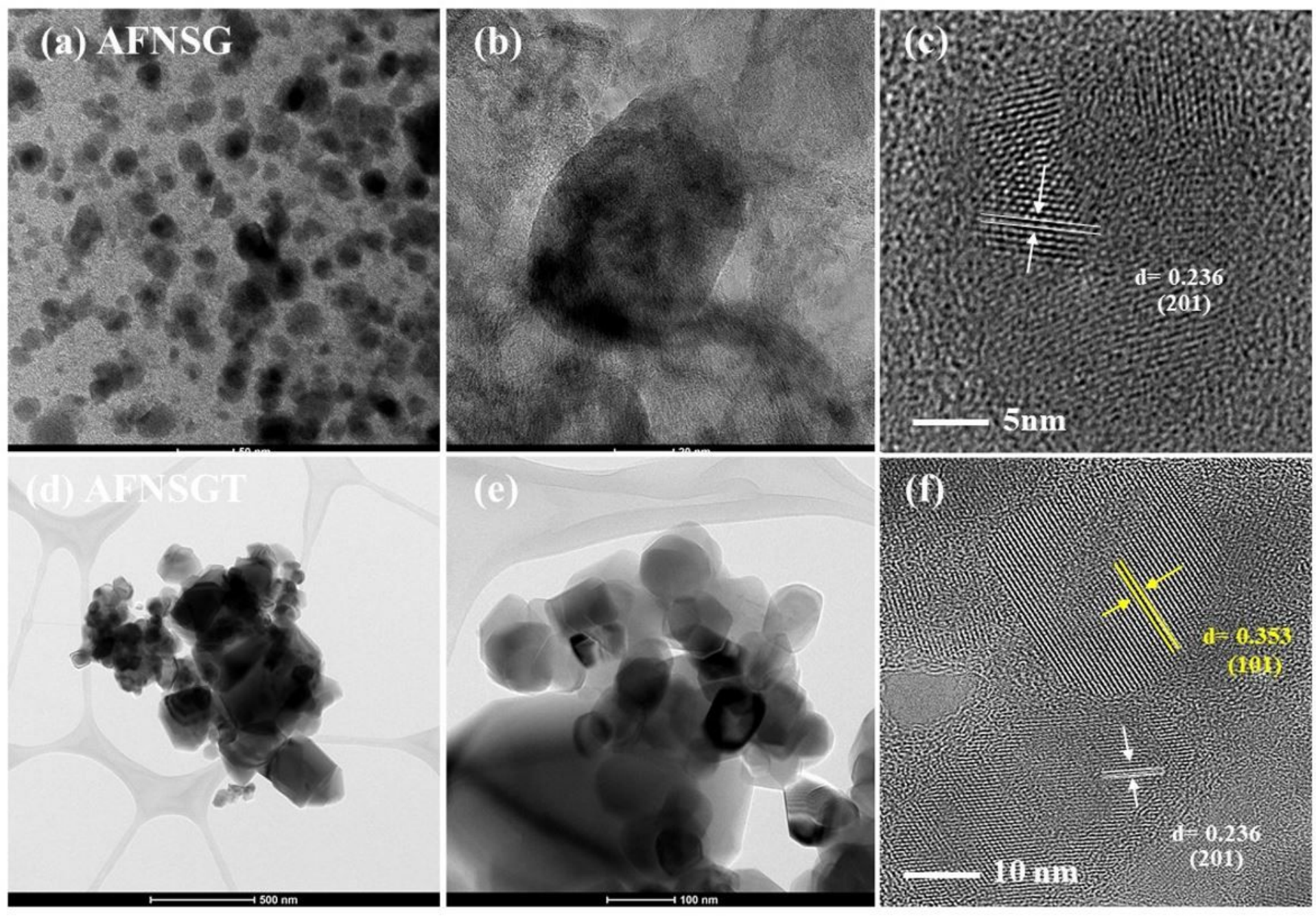

Figure 4

TEM image ; (a-b) AgFeNi2S4-Graphene, (d-e) AgFeNi2S4-Graphene-TiO2, and (c, f) HRTEM images of AFNSG and AFNSGT. 

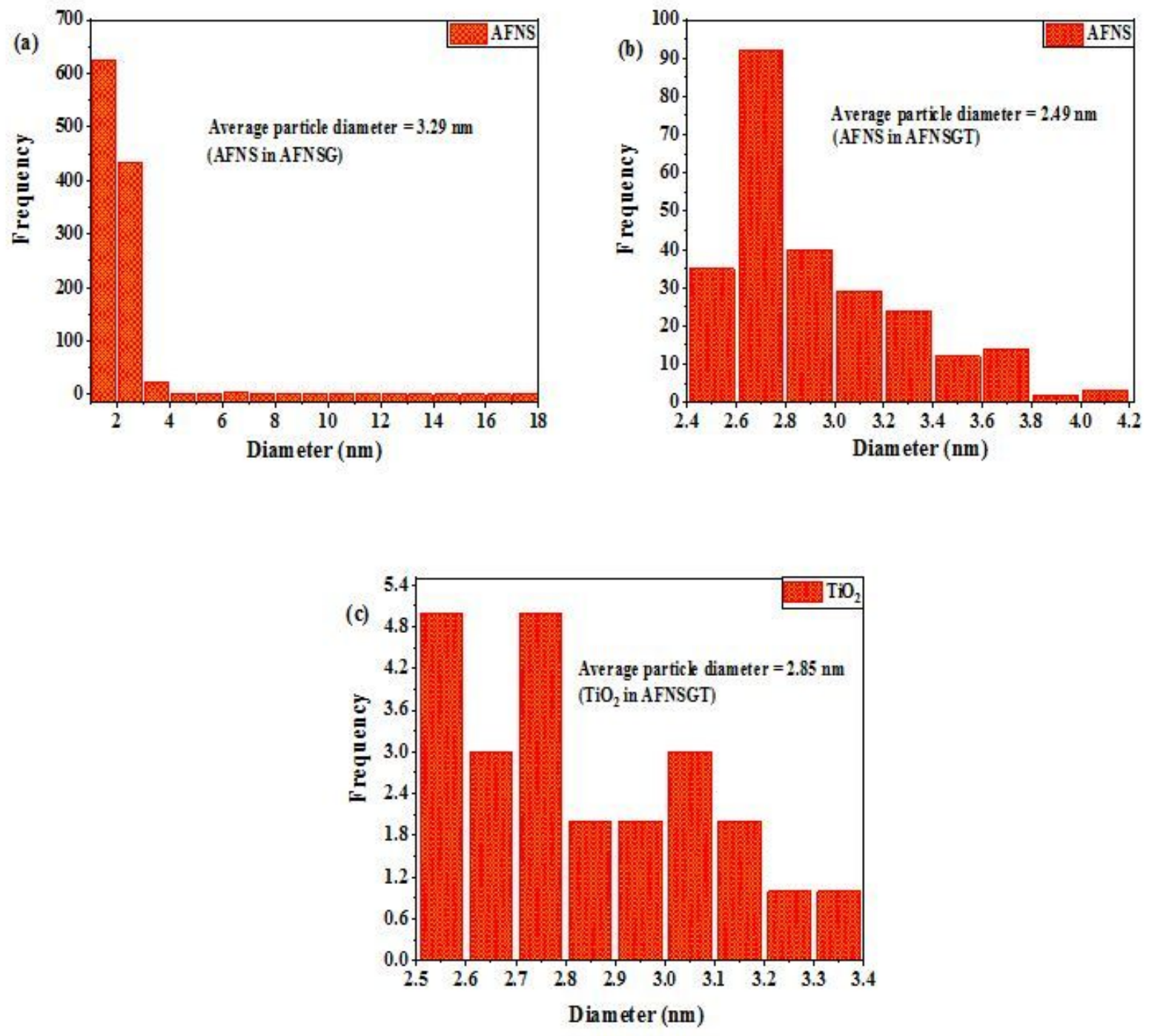

(d)
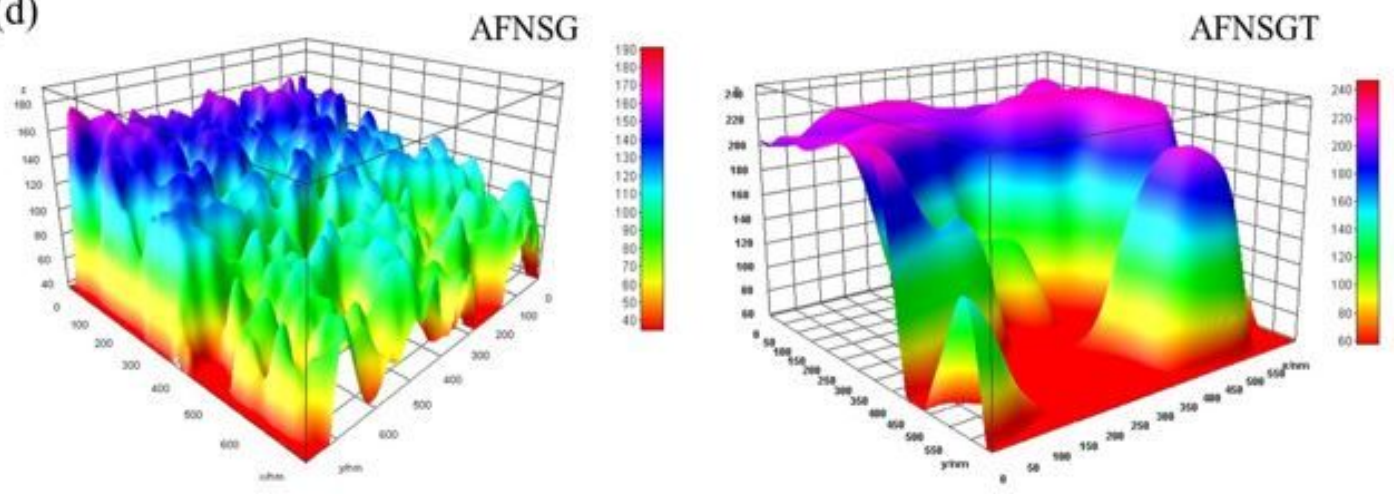

Figure 5

Nanoparticle-size histogram of (a-c) AgFeNi2S4 and, TiO2 in all samples, (d) Interactive 3D surface plot. 


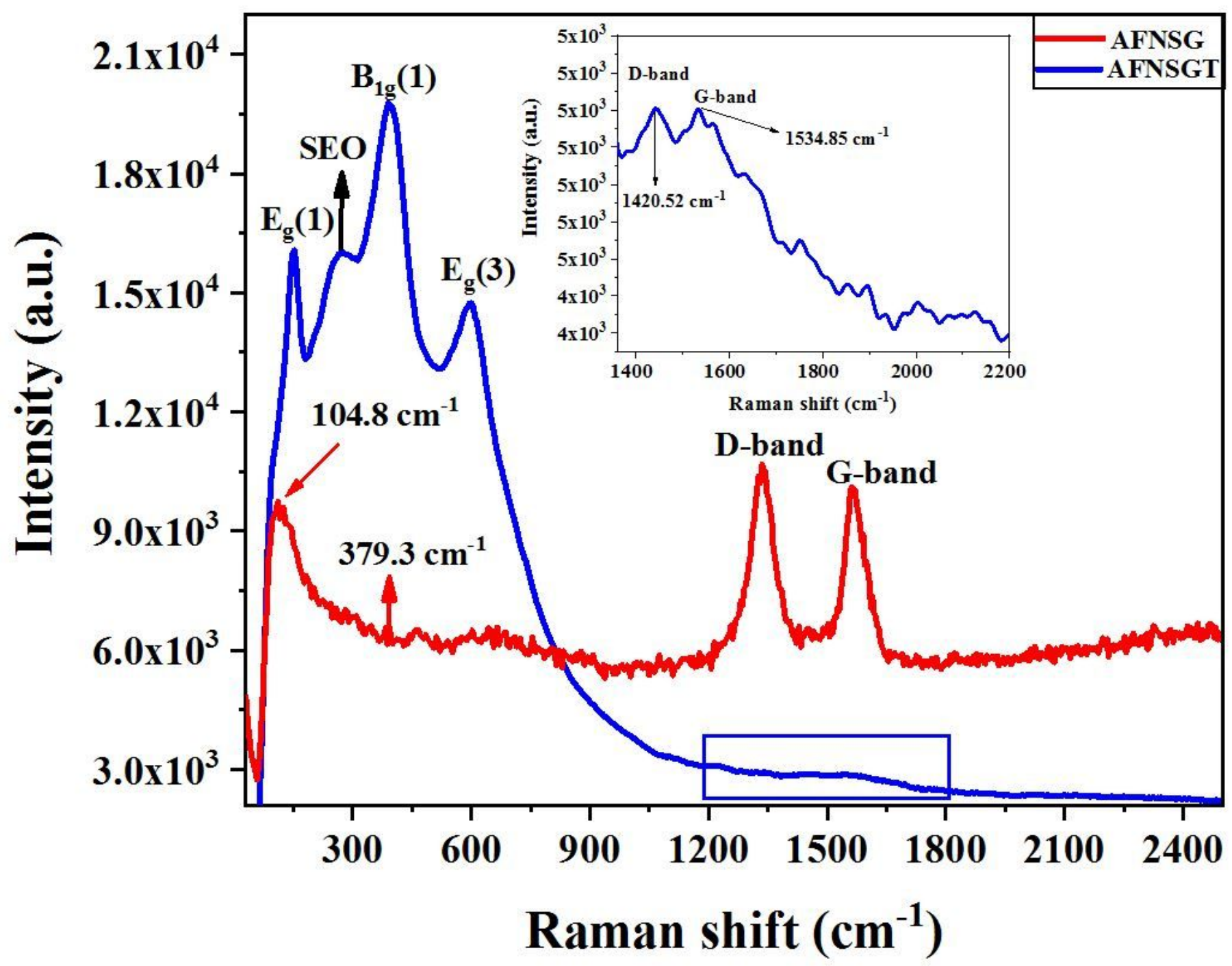

Figure 6

Raman spectra of AgFeNi2S4-Graphene, AgFeNi2S4-Graphene-TiO2. 

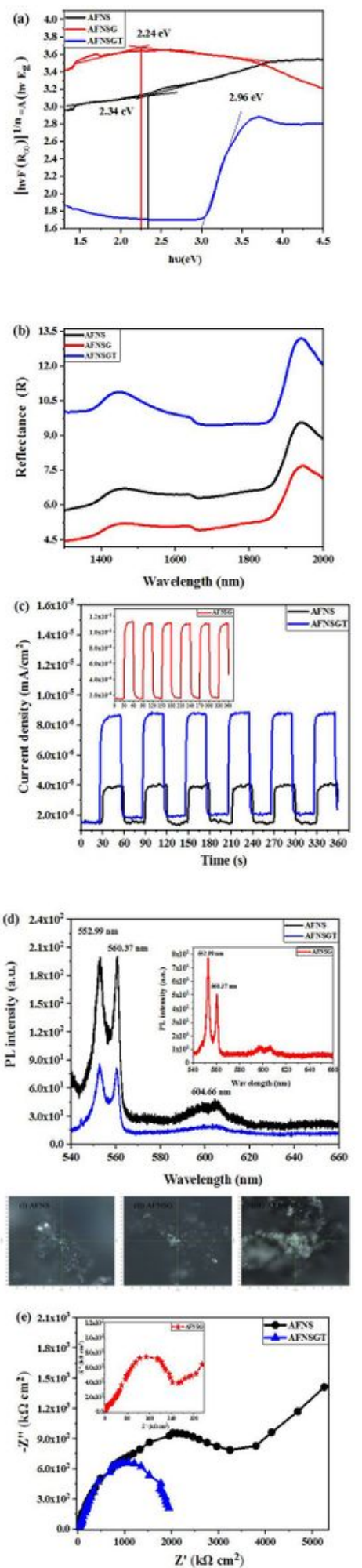

Figure 7

(a) DRS and (b) reflectance spectra, (c) Photocurrent analysis, (d) Photoluminescence spectra, (e) Nyquist plot of AgFeNi2S4, AgFeNi2S4-Graphene and AgFeNi2S4-Graphene-TiO2. 

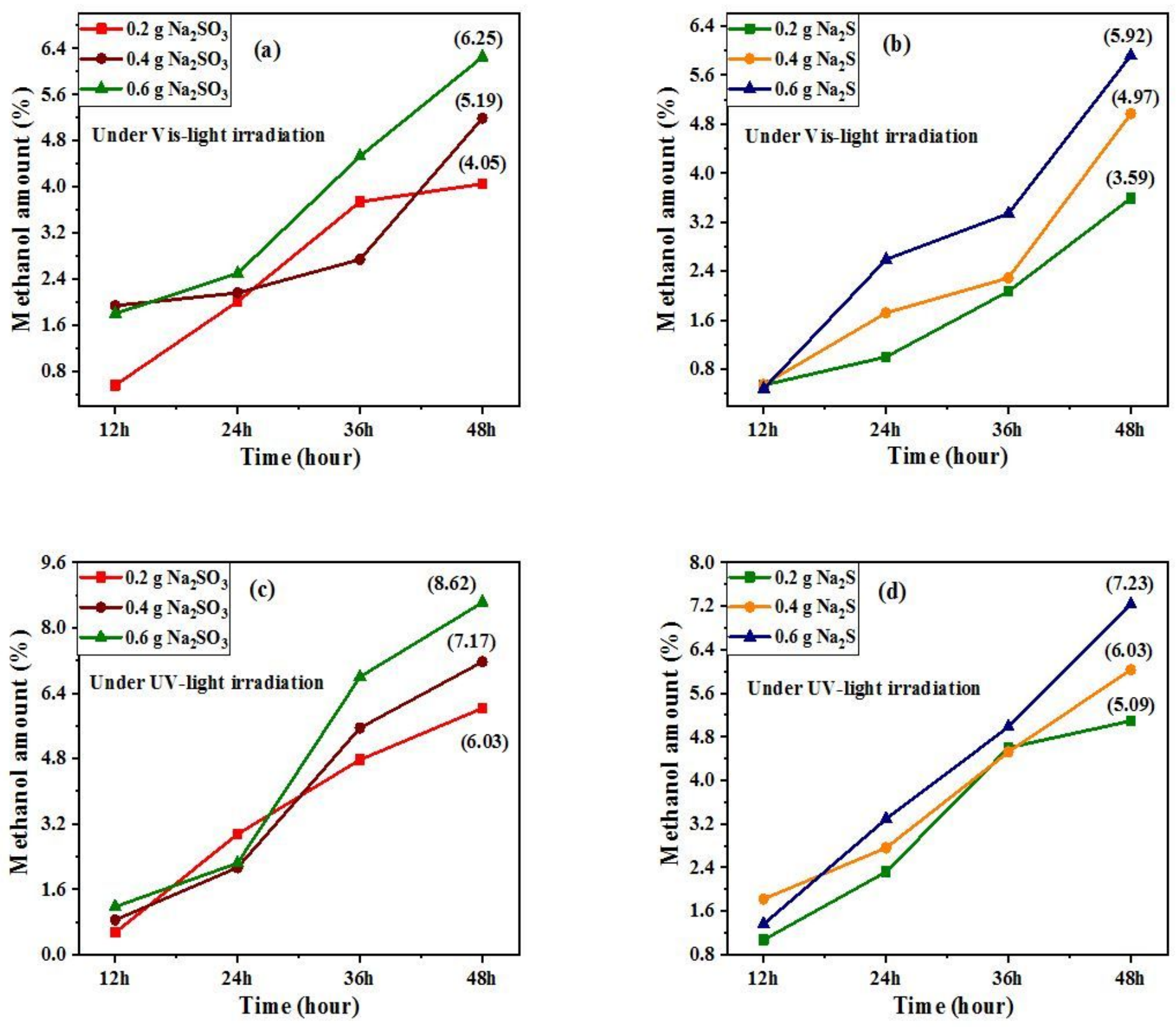

Figure 8

Quantitative analysis of Alcohol result of AgFeNi2S4-Graphene-TiO2 ternary composite under (a) Visible light, (b) UV light using a different amount of scavenger. 

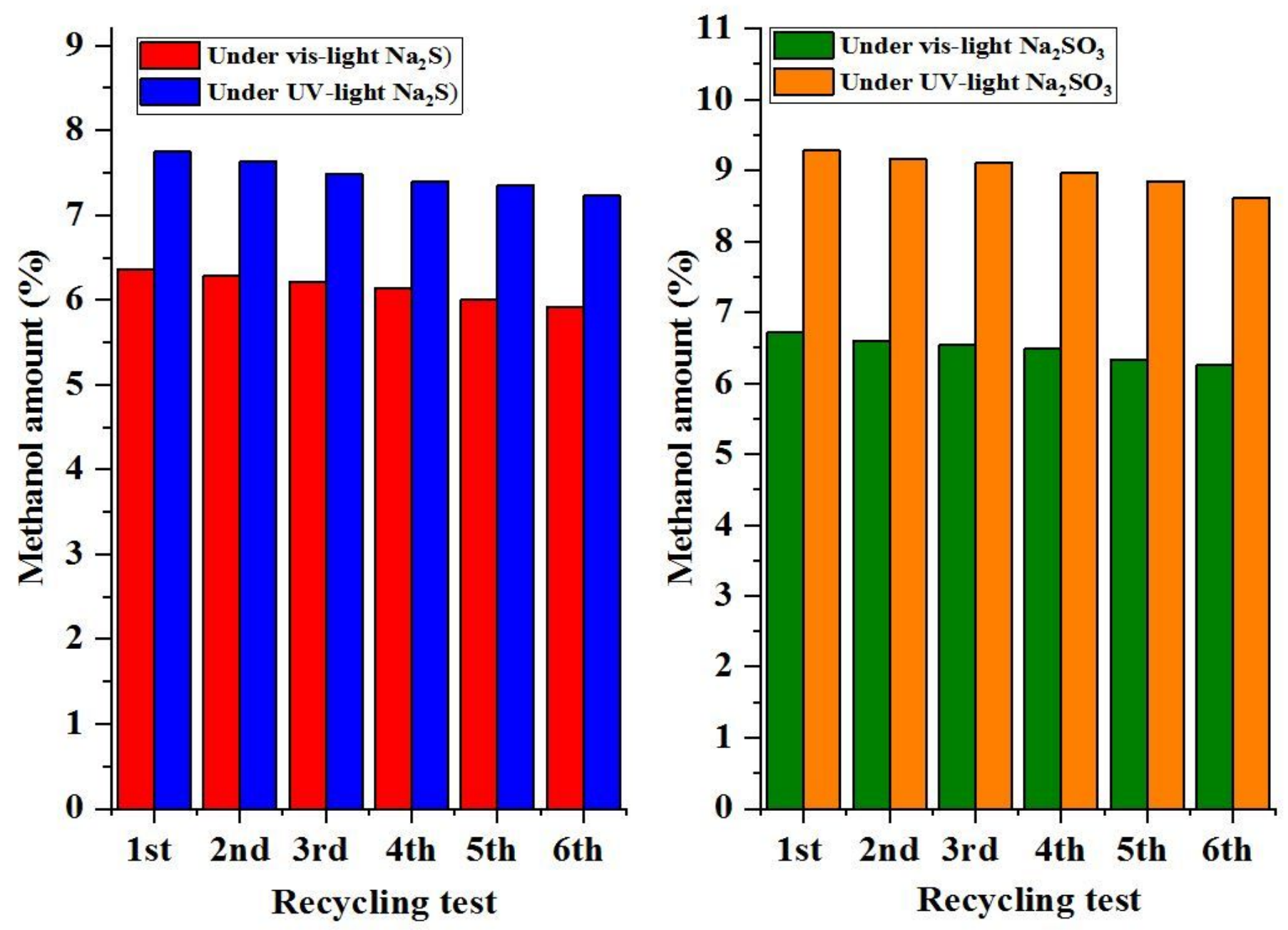

Figure 9

Recycling test of AgFeNi2S4-Graphene-TiO2 ternary composite under the Vis/UV-light with two scavengers. 


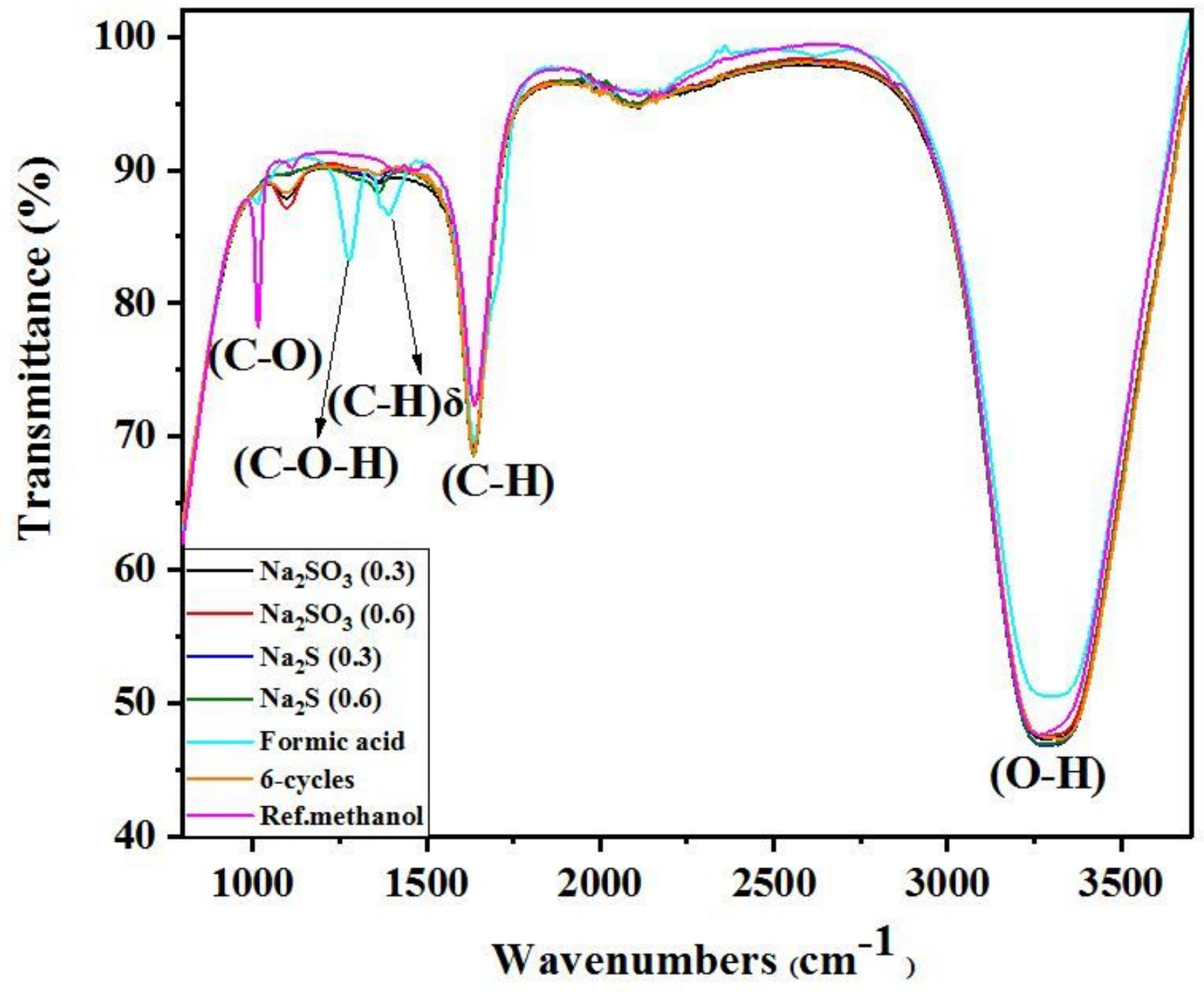

Figure 10

The FTIR result of the final product: reference (olive line), final methanol product (blue and red line). 


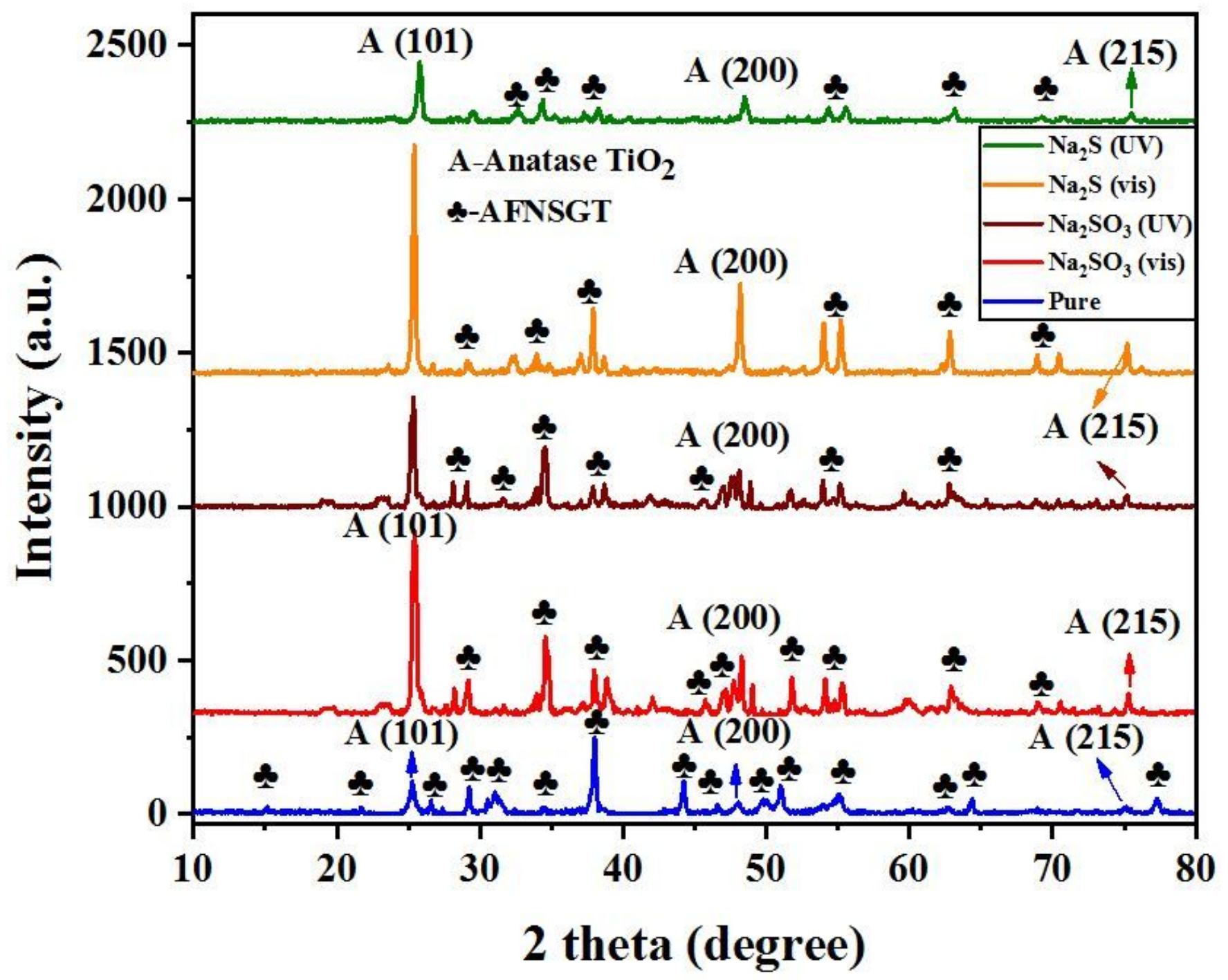

Figure 11

XRD pattern of AgFeNi2S4-Graphene-TiO2 ternary composite (after photocatalytic $\mathrm{CO} 2$ reduction).

\section{Supplementary Files}

This is a list of supplementary files associated with this preprint. Click to download.

- scheme1.jpg 